\title{
Fatores que interferem no cumprimento do calendário vacinal na infância
}

\author{
Factors that interfere with the fulfillment of the childhood immunization schedule \\ Factores que interfieren en el cumplimiento del calendario de vacunación en la infância \\ Maria Clara Gomes Araújo ${ }^{1}$, Liliane Ferreira da Silva1 ${ }^{1}$ Luciana Stanford Baldoino ${ }^{1 *}$, Tatiana Naiana \\ Rodrigues dos Santos Porto ${ }^{1}$, Vinícius de Sousa Martins ${ }^{1}$, Dorivaldo Pereira Carvalho ${ }^{1}$, Benedito \\ Pereira de Sousa Neto ${ }^{1}$, Nilton Andrade Magalhães ${ }^{1}$, Lorena Stanford Baldoino².
}

\section{RESUMO}

Objetivo: Analisar quais os fatores que interferem no cumprimento da atualização do calendário vacinal da infância. Métodos: Trata-se de uma pesquisa descritiva, exploratória com abordagem quantitativa realizada em uma Unidade Básica de Saúde do município de São José dos Matões-MA. Participaram da pesquisa 51 crianças com a faixa etária de 0 a 4 anos, as quais os pais ou responsáveis apresentaram a caderneta de vacinação da criança com a folha de registro das vacinas. Resultados: Evidenciou-se que os imunobiológicos que obtiveram mais doses com atrasos foram: meningocócica $(18,18 \%)$, pneumocócica $(16,67 \%)$, Pentavalente $(9,09 \%)$, DTP $(7,58 \%)$, Tetraviral (7,58\%), Febre Amarela (7,58\%), Hepatite A $(7,58 \%)$, Rotavírus $(7,58 \%)$, VIP $(6,06 \%)$ e VOP $(6,06 \%)$. Constatou-se que os principais fatores encontrados foram criança fora da faixa etária $(30,77 \%)$, criança adoecia $(27,69 \%)$, esquecimento $(15,38 \%)$, não quis levar a criança $(10,77 \%)$ e outros motivos (falta de tempo, falta de imunológico no posto) $(6,15 \%)$. Considerações finais: Os fatores que levam ao descumprimento podem ser diversos, desde fatores sociais ou relacionados à saúde, houve um elevado número de crianças fora da faixa etária adequada para a administração do imunobiológico recomendado, o que dificulta assim o alcance da cobertura vacinal.

Palavras-chave: Vacinação em massa, Programas de imunização, Esquemas de imunização.

\begin{abstract}
Objective: To analyze which factors interfere with the fulfillment of the childhood vaccination calendar update. Methods: This is a descriptive, exploratory research with a quantitative approach conducted in a Basic Health Unit of the municipality of São José dos Matões-MA. Fifty-one children from 0 to 4 years of age participated in the survey, and their parents or guardians presented the child's vaccination booklet with the vaccine registration sheet. Results: The immunobiologicals that obtained the most delayed doses were: meningococcal (18.18\%), pneumococcal (16.67\%), Pentavalent $(9.09 \%)$, DTP $(7.58 \%)$, Tetraviral $(7.58 \%)$, Yellow Fever (7.58\%), Hepatitis A (7.58\%), Rotavirus (7.58\%), VIP $(6.06 \%)$, and OPV (6.06\%). It was found that the main factors found were children outside the age range $(30.77 \%)$, sick children $(27.69 \%)$, forgetfulness $(15.38 \%)$, unwilling to take the child $(10.77 \%)$, and other reasons (lack of time, lack of immunology in the post) $(6.15 \%)$. Final considerations: The factors leading to non-compliance can be diverse, from social or healthrelated factors, there was a high number of children out of the appropriate age group for the administration of the recommended immunobiological, which makes it difficult to reach vaccination coverage.
\end{abstract}

Keywords: Immunization in mass, Immunization programs, Immunization schemes.

${ }^{1}$ Faculdade de Ensino Superior Múltiplo (IESM), Timon-MA. *E-mail: Isbaldoino@hotmail.com

${ }^{2}$ Graduação em Fisioterapia pelo Centro Universitário (UNINOVAFAPI), Teresina-PI.

SUBMETIDO EM: 1/2020

ACEITO EM: 2/2020

PUBLICADO EM: $3 / 2020$ 


\section{RESUMEN}

Objetivo: Analizar qué factores interfieren en el cumplimiento de la actualización del calendario de vacunación infantil. Métodos: Se trata de una investigación descriptiva y exploratoria con enfoque cuantitativo, realizada en una Unidad Básica de Salud del municipio de São José dos Matões-MA. Participaron en la encuesta 51 niños de 0 a 4 años de edad, y sus padres o tutores presentaron el cuaderno de vacunación del niño con la hoja de registro de vacunas. Resultados: Los inmunobiológicos que obtuvieron las dosis más tardías fueron: meningococo $(18,18 \%)$, neumococo $(16,67 \%)$, pentavalente $(9,09 \%)$, DTP $(7,58 \%)$, tetraviral $(7,58 \%)$, fiebre amarilla $(7,58 \%)$, hepatitis A $(7,58 \%)$, rotavirus $(7,58 \%)$, VIP $(6,06 \%)$ y OPV $(6,06 \%)$. Se encontró que los principales factores encontrados fueron niños fuera del rango de edad $(30,77 \%)$, niños enfermos $(27,69 \%)$, olvido $(15,38 \%)$, falta de voluntad de tomar al niño (10,77\%), y otras razones (falta de tiempo, falta de inmunología en el puesto) $(6,15 \%)$. Consideraciones finales: Los factores que conducen al incumplimiento pueden ser diversos, desde factores sociales o sanitarios, hubo un alto número de niños fuera del grupo de edad apropiado para la administración del inmunobiológico recomendado, lo que dificulta el logro de la cobertura de vacunación.

Palabras-clave: Inmunización en masa, Programas de inmunización, Esquemas de inmunización.

\section{INTRODUÇÃO}

A Atenção Básica é considerada um conjunto de ações, que engloba formas de promoção, proteção da saúde, prevenção de agravos, o diagnóstico, o tratamento e a reabilitação da saúde tanto no campo individual como no coletivo. Tendo como principal objetivo o desenvolvimento de uma ação integrada que possa melhorar a situação de saúde e autonomia dos indivíduos e nos determinantes e condicionantes da saúde da coletiva (BRASIL, 2012).

O enfermeiro é integrante da equipe de saúde, e tem como compromisso realizar ações que visem à saúde. Sua responsabilidade é atender tanto as diretrizes do Programa Nacional de imunização com os da Política Nacional de Atenção, que buscam orientar as ações realizadas nesse nível de atenção (TAVARES RE, TOCATINS FR, 2015).

O indivíduo se torna imune de agentes causadores de infecção, através de um processo chamado Imunização, que é a administração de vacinas e imunoglobulinas. Essas vacinas podem ser proteínas, toxinas fragmentadas de bactérias e vírus, ou até mesmo esses agentes inteiros, vivos atenuados ou mortos, que entram em contato com o sistema imunológico de um animal, resumem uma serie de reações imunológicas que podem tornar o organismo completamente imune ao agente causador da infecção, protegendo-o também de posteriores infecções ou doenças infecciosas causadas por esse agente (NÓBREGA LAL, et al., 2016).

Vale salientar que o Programa Nacional de Imunização disponibiliza vacinas para o calendário básico. São elas: BCG, hepatite B, vacina oral contra poliomielite, vacina tetravalente (DTP + Hib, que agem contra difteria, tétano, coqueluche e infecções pelo Haemophilus influenzae tipo b), vacina contra febre amarela, tríplice viral (que age contra sarampo, caxumba e rubéola), tríplice bacteriana DTP (que agem contra difteria, tétano e coqueluche), dupla bacteriana DT (que age contra difteria e tétano), influenza, rotavírus, pneumocócica 10 (que agem contra doenças causadas por Pneumococo) e meningocócica $C$ (que agem contra doenças causadas por Neisseria meningitidis do sorogrupo C) (MARTINS AF, et al., 2014).

O Ministério da Saúde estabelece metas para a cobertura vacinal, são elas: 80\% para HPV e Influenza, 90\% para a vacina BCG e VORH, 95\% para as vacinas Hepatite B, Pentavalente, Poliomielite, Pneumo 10, Meningo C, Tríplice Viral, Tetra e hepatite A e de 100\% para Febre Amarela, dT e dTpa (BRASIL, 2014).

Para Oliveira MAF (2014), os principais fatores que possam interferir na cobertura vacinal na infância são: crianças não possuírem a caderneta de vacina, vacinas com múltiplas doses, aumento da idade, desigualdade especialmente da cobertura, fatores familiares e acesso a serviços de saúde.

Devido haver grandes porcentagens de atrasos nos calendários básicos de vacinação, é necessário que haja ações voltadas para a imunização na primeira infância, tendo como principal finalidade diminuir e/ou 
evitar doenças que possam interferir na qualidade de vida das crianças, com atualizações dos imunobiológicos, os profissionais responsáveis pelo cumprimento do calendário vacinal devem se manter atentos para realizarem a cobertura vacinal de forma eficaz (CAVALCANTE CCFS, 2015).

O Monitoramento Rápido de Coberturas vacinais (MRC) é uma atividade recomendada pela Organização Pan-Americana de Saúde (OPAS) para que seja realizada a supervisão das ações de vacinação adotada em vários países das Américas como uma ação rotineira. É um método extremamente útil para definir ou redefinir ações de vacinação, para melhorar as coberturas vacinais e homogeneidade de coberturas (BRASIL, 2017).

Dessa forma, a imunização torna-se um instrumento de prevenção de doenças imunopreveníveis, esse estudo além de identificar os fatores que possam interferir no não cumprimento das metas preconizadas para o calendário vacinal da infância, ajudará os profissionais da saúde a conseguirem cumprir as metas através da busca ativa das crianças com atraso vacinal e das demais estratégias que estão preconizadas pelo Ministério da Saúde.

Assim, o estudo torna-se relevante devido à importância de ofertar conhecimento sobre os imunobiológicos, e tornar os profissionais mais qualificados para o desempenho dessa função, e levar mais informações e qualidade de vida para população, demonstrando a importância e os benefícios da imunização (OLIVEIRA MAF, et al., 2016).

Tendo em vista a problemática exposta, elaborou-se a seguinte questão norteadora: Quais são os principais fatores que podem interferir no cumprimento das metas preconizadas para a cobertura vacinal na infância? Diante do exposto, o presente estudo objetivou analisar os fatores que interferem no cumprimento da atualização do calendário vacinal da infância.

\section{MÉTODOS}

Trata-se de uma pesquisa descritiva, exploratória e com abordagem quantitativa, realizada uma investigação por meio da análise das cadernetas infantis de crianças residentes da área urbana de São José dos Matões-Maranhão, sendo o instrumento da pesquisa o Protocolo de Monitoramento Rápido de Cobertura vacinal (MRC), utilizando o Boletim para registro da situação vacinal encontrada.

O presente trabalho foi realizado em uma Unidade Básica de Saúde (UBS) localizada no interior do Maranhão, com uma população de 31.015 pessoas. Tendo a taxa de mortalidade infantil média na cidade de 17.09 para 1.000 nascidos vivos (OLIVEIRA MFS, et al., 2014).

Vale ressaltar que essa UBS está localizada no bairro Seriema, que faz parte do subúrbio da cidade. Esta instituição é composta por duas equipes da Estratégia de Saúde da Família (ESF), sendo; que cada equipe possui um médico, um enfermeiro, um técnico de enfermagem e de cinco a dez Agentes Comunitários de Saúde (ACS).

O universo deste estudo inicialmente foram exatamente 60 participantes $(n=60)$, dados obtidos por meio dos cartões sombras das agentes comunitárias, onde seriam os cartões das crianças de 0 a 4 anos, 11 meses e 29 dias com a folha de registro de vacinas presentes no cartão, durante a pesquisa obteve-se informações de apenas 51 crianças, o que representa $85 \%$, as outras 09 crianças (15\%), não participaram da pesquisa por recusa dos responsáveis.

No segundo momento foi aplicado um questionário autoexplicativo e padronizado para que a mãe ou responsável responda por essas crianças. Os instrumentos que foram utilizados para coleta de dados foram à caderneta da criança e o Protocolo de Monitoramento Rápido de Cobertura vacinal (MRC), sendo utilizado o Boletim para registro da situação vacinal encontrada.

Está pesquisa teve como critério de inclusão crianças com idade entre 0 a 4 anos, 11 meses e 29 dias como também da caderneta da criança contemplando a folha de registro de vacina. Já com relação aos critérios de exclusão foram as crianças com cartões de vacinas sem a folha de registro de vacinas ou sem um acompanhante responsável.

A coleta das informações foi realizada em setembro de 2018 e somente após aprovação do Comitê de Ética em Pesquisa (CEP) do Hospital São Marcos. Na coleta de dados foram levantadas informações a 
respeito da caderneta no que tange o esquema vacinal da criança que foi avaliada e também foi aplicado um questionário autoexplicativo e padronizado à mãe ou responsável.

Assim, os dados foram coletados por meio da análise dos registros das vacinas na caderneta da criança baseado no calendário vacinal do Ministério da Saúde 2018, esses dados foram registrados em um boletim para registro da situação vacinal encontrada conforme estabelecido pelo Ministério da Saúde, logo após foi realizada a entrevista com a genitora da criança ou responsável com um questionário presente nesse mesmo boletim.

Os participantes da pesquisa ainda assinaram um Termo de Consentimento Livre Esclarecido e foram informados sobre os objetivos do estudo, onde foram lhe assegurados ainda, o direito à privacidade, sigilo, acesso aos dados, bem como a liberdade de se retirar do estudo, se assim o convier.

Vale enfocar que o Termo de Consentimento Livre e Esclarecido (TCLE) foi entregue aos genitores e/ou responsável pela criança, no qual constava a possibilidade da criança ou responsável não participar da pesquisa, como também foram informados quanto aos benefícios que os resultados trarão à população, sendo garantido a privacidade durante a aplicação do questionário aos participantes desta pesquisa.

Dessa forma, os dados foram analisados por meio da estatística descritiva simples (distribuição e percentual) das respostas obtidas por esses dois instrumentos e em seguida houve a identificação e os principais fatores que estão interferindo no não cumprimento das metas preconizadas pelo Ministério da Saúde para o calendário vacinal da infância onde foram organizados e digitados no bloco de texto do Microsoft Word $\AA$, além de gráficos, tabelas que foram construídos a partir do Microsoft Excel $\AA^{\circledR}$, buscando repassar todas as respostas encontradas durante a pesquisa que contribuíram para o estudo.

Em relação aos benefícios da pesquisa, os participantes contribuíram com informações para o presente estudo ao participar da pesquisa que não trouxe nenhum dano a sua integridade física e moral, conhecendo assim os benefícios do calendário vacinal.

Os dados foram utilizados somente para análise, interpretação e divulgação de informações em saúde por meio de publicações científicas e artigos científicos, todas estas informações estavam inseridas no TCLE na pesquisa.

Os possíveis riscos foram constituídos de riscos não-físicos, como os de origem psicológica, uma vez que puderam, em algum momento, sentirem-se constrangidos. Estes foram minimizados por meio de uma abordagem compreensiva e isenta de julgamentos, da preservação da identidade e garantia de sigilo das informações.

\section{RESULTADOS}

Os dados foram organizados em tabelas e gráficos, obtendo características sociodemográficos da criança e dos responsáveis que responderam por essa criança, além de dados sobre os principais imunobiológicos encontrados com atraso e os principais fatores que levaram a esse atraso.

Os dados sociodemográficos referentes às crianças, revelando que do total geral de 51 crianças (85\%) que tiveram suas cadernetas avaliadas, observou-se que cerca de 25 crianças eram do sexo feminino, o que representa $49,02 \%$ do total, e 26 eram do sexo masculino, o que diz respeito a 50,98\% (Tabela 1). 
Tabela 1 - Características sociodemográficas das crianças alvo da pesquisa segundo sexo e idade, da cidade São José dos Matões-Maranhão, Timon-MA. Brasil, 2020.

\begin{tabular}{lcr}
\hline Variáveis & $\mathbf{N}$ & $\%$ \\
\hline Sexo & 25 & 49,02 \\
Feminino & 26 & 50,98 \\
Masculino & $\mathbf{5 1}$ & $\mathbf{1 0 0 , 0 0}$ \\
Total & & \\
\hline Idade das crianças por sexo (meses e anos) & 24,00 \\
\hline Feminino & 6 & 24,00 \\
$02 \mathrm{~m}-07 \mathrm{~m}$ & 6 & 24,00 \\
$08 \mathrm{~m}-1 \mathrm{a}$ & 6 & 20,00 \\
1a1m-1a6m & 5 & 8,00 \\
1a7m-1a11m & 2 & $\mathbf{1 0 0 , 0 0}$ \\
2a-4 & $\mathbf{2 5}$ & \\
\hline Total & & 7,69 \\
\hline Masculino & 2 & 19,23 \\
$02-07 \mathrm{~m}$ & 5 & 34,62 \\
$08 \mathrm{~m}-1 \mathrm{a}$ & 9 & 30,77 \\
1a1m-1a6m & 8 & $\mathbf{1 0 0 , 0 0}$ \\
1a7m-1a11m & $\mathbf{2 6}$ &
\end{tabular}

Fonte: Araújo MCG, et al., 2020.

De acordo com os dados sociodemográficos referentes à idade dos responsáveis das crianças que tiveram suas cadernetas avaliadas, percebeu-se que cerca de $31,37 \%$ dos responsáveis tinham idade média de 22 anos a 27 anos, enquanto 23,52\% tinha entre 16 anos a 21 anos de idade, valor que representa também a faixa etária de 28 anos a 32 anos (23,52\%) (Tabela 2$)$.

Tabela 2 - Percentual da idade dos responsáveis das crianças alvo da pesquisa da cidade São José dos Matões-Maranhão, Timon-MA. Brasil, 2020.

\begin{tabular}{c|cc}
\hline Variáveis (anos) & $\mathbf{N}$ & $\%$ \\
\hline Idades & 12 & 23,52 \\
\hline $16 a-21 a$ & 16 & 31,37 \\
$22 a-27 a$ & 12 & 23,52 \\
$28 a-32 a$ & 6 & 11,76 \\
$33 a-37 a$ & 2 & 3,92 \\
$38 a-42 a$ & 2 & 3,92 \\
$43 a-47 a$ & 1 & 1,96 \\
$48 a-52 a$ & $\mathbf{5 1}$ & $\mathbf{1 0 0 , 0 0}$ \\
\hline Total & &
\end{tabular}

Fonte: Araújo MCG, et al., 2020. 
O Gráfico 1, apresenta informações sociodemográficos acerca da ocupação do responsável pela criança, dos 51 responsáveis entrevistados, evidenciou-se que $76,47 \%$ não trabalhavam, enquanto cerca de $23,53 \%$ trabalhavam fora de casa.

Gráfico 1 - Distribuição percentual da ocupação dos responsáveis pelas crianças participantes da pesquisa da cidade São José dos Matões-Maranhão, Timon- MA. Brasil, 2020.



Fonte: Araújo MCG, et al., 2020.

No Gráfico 2, demonstra-se o total de crianças por sexo que apresentaram atraso vacinal no calendário básico de vacinas. No estudo quanto aos dados que estão distribuídos com relação ao sexo com maior predominância, percebeu-se que 58,33\% eram do sexo masculino dos casos de crianças com vacinas atrasadas, enquanto o sexo feminino obteve $41,67 \%$ de casos de vacinas atrasadas.

Gráfico 2 - Distribuição percentual do total de crianças com atraso de dose no calendário básico de vacina, Timon-MA. Brasil, 2020.



Fonte: Araújo MCG, et al., 2020.

De acordo com o Gráfico 3, evidenciou-se que os imunobiológicos que obtiveram mais doses com atrasos foram: meningocócica $(18,18 \%)$, pneumocócica $(16,67 \%)$, Pentavalente $(9,09 \%)$, DTP $(7,58 \%)$, Tetraviral 
(7,58\%), Febre Amarela (7,58\%), Hepatite A (7,58\%), Rotavírus (7,58\%), VIP (6,06\%) e VOP (6,06\%), as vacinas com menos doses atrasadas foram: Tríplice viral $(4,55 \%)$ e BCG $(1,52 \%)$.

Constatou-se então por meio da análise da folha de registro de vacinas que os imunobiológicos que obtiveram maiores atrasos são os que existem duas ou mais doses, o que leva a uma maior dificuldade de retorno do responsável por essa criança ao estabelecimento de saúde para ser realizada a administração daquele imunobiológico dentro da faixa etária correta, impossibilitando assim o cumprimento do calendário vacinal e o atingimento da meta preconizada pelo Ministério da Saúde.

Gráfico 3 - Distribuição percentual dos imunobiológicos com doses atrasadas encontradas no calendário básico das crianças participantes da pesquisa da cidade São José dos Matões-MA, Timon-MA. Brasil, 2020.

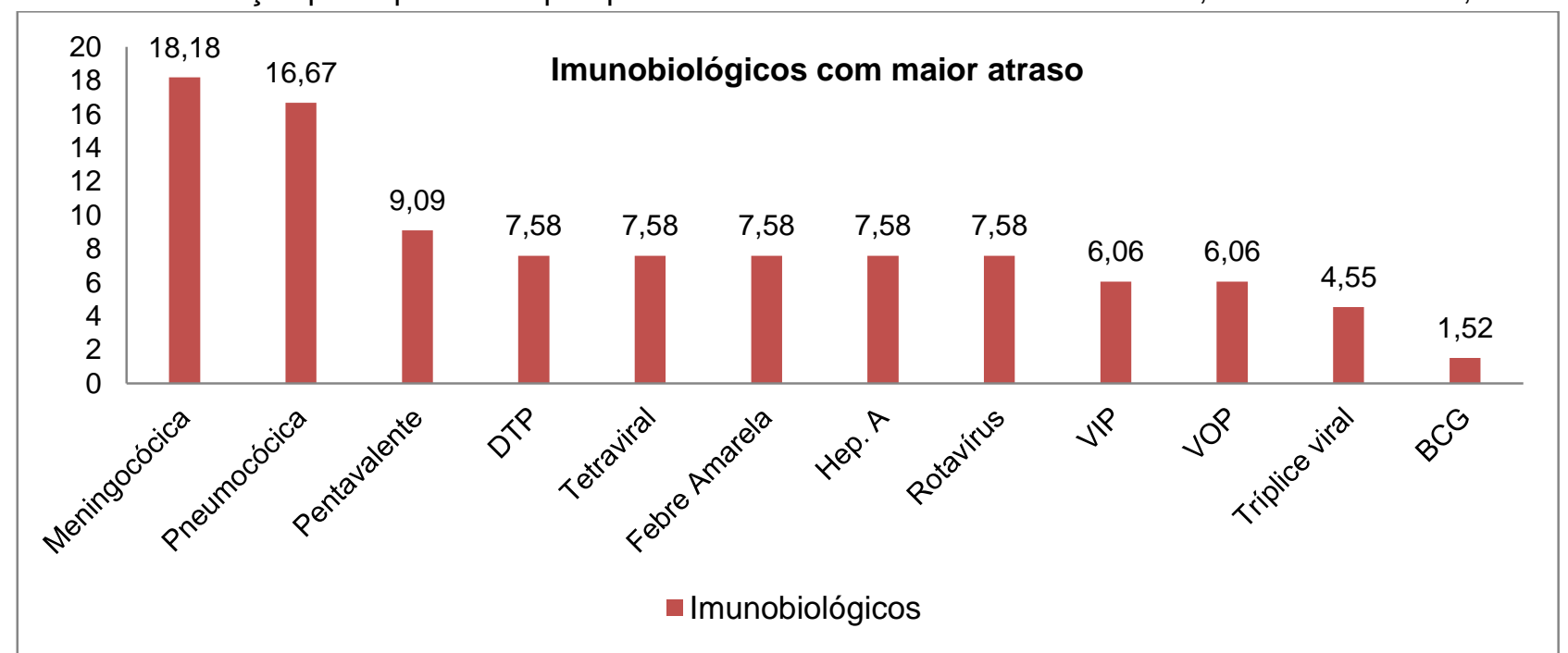

Fonte: Araújo MCG, et al., 2020.

O Gráfico 4, demonstra a distribuição percentual dos principais fatores que levaram ao atraso do calendário básico de vacinas, esses fatores foram obtidos através da entrevista com os responsáveis pelas crianças alvo da pesquisa. Constatou-se que os principais fatores encontrados foram criança fora da faixa etária $(30,77 \%)$, criança adoecia $(27,69 \%)$, esquecimento $(15,38 \%)$, não quis levar a criança $(10,77 \%)$ e outros motivos (falta de tempo, falta de imunológico no posto) $(6,15 \%)$.

Gráfico 4 - Distribuição percentual dos principais fatores encontrados para o atraso do calendário básico de vacinas da cidade São José dos Matões-Maranhão, Timon-MA. Brasil, 2020.

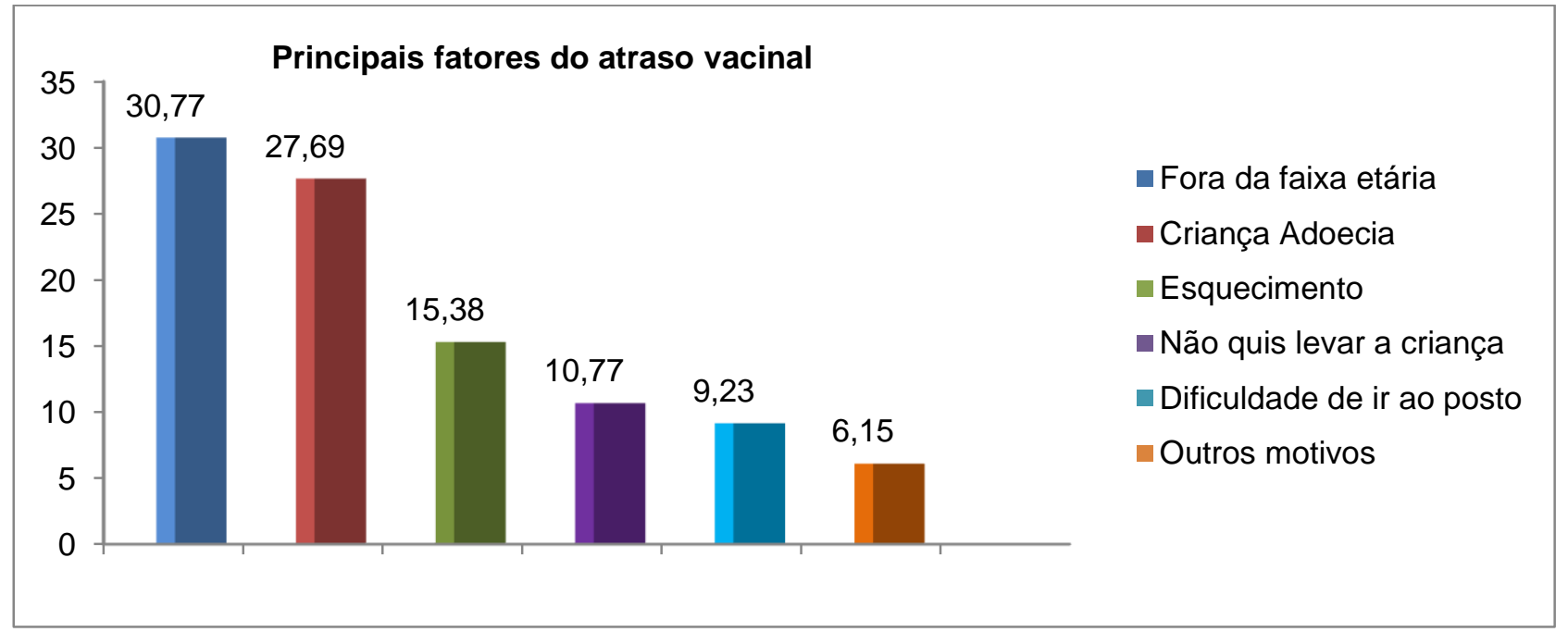

Fonte: Araújo MCG, et al., 2020. 


\section{DISCUSSÃO}

Uma das características sociodemográficas pesquisadas durante a coleta de dados, foi a idade das crianças, o maior número de crianças estava na faixa etária entre 2 meses há 1 ano de idade, logo em seguida a faixa etária de 1 ano e 7 meses há 1 ano e 11 meses, crianças de 2 anos até 4 anos representaram o menor número de crianças dos participantes. Cavalcante CCFS et al. (2015) observaram durante um estudo sobre as vacinas do esquema básico para o primeiro ano de vida em atraso em município do Nordeste Brasileiro, que 33,6\% apresentavam idade entre 10 a 12 meses e que 24,4\% apresentavam idade entre 0 a 3 meses.

O sexo masculino obteve maior número de crianças com atraso no calendário vacinal, enquanto o sexo feminino obteve menor quantidade de atrasos no calendário. Resultados diferentes foram encontrados por Sally ET e Kenu E (2017), em um estudo que avaliou o acesso e utilização de serviços do Expanded Programme of Immunization (EPI) entre crianças 12-23 meses em Kwahu Afram Plains, região leste,

Gana. Constatou-se no estudo que um dos fatores sociodemográficos que interferem na cobertura vacinal é o sexo da criança, através da análise dos dados obtidos durante a pesquisa, houve mais predominância de crianças do sexo feminino, porém o sexo masculino é o que mais obteve registro total de imunização com $41,5 \%$, enquanto o sexo feminino obteve $39,8 \%$ total de registros.

As maiores faixas etárias dos responsáveis participantes da pesquisa variaram de 22 a 27 anos. Andrade DRS et al. (2014) verificaram durante uma pesquisa que avaliava o conhecimento das mães sobre 0 calendário de vacinação e fatores que levam ao atraso vacinal infantil que a faixa etária varia entre 18 e 49 anos, demonstrando assim que a idade das mães não é considerada um fator de avaliação.

Os principais imunobiológicos que apresentaram esquema incompleto foram Meningocócica $\mathrm{C}$ e Pneumocócica 10 valente, e o imunobiológico que obteve o menor percentual de esquema incompleto foi à vacina BCG. Em estudo Dona D et al. (2018), perceberam que as vacinas BCG e a poliomielite são as vacinas que obtém mais percentuais de esquema completo, enquanto as vacinas meningocócica $C(32,2 \%)$ e pneumocócica 10 valente $(48,9 \%)$ são as que obtém maiores percentuais relacionados ao esquema incompleto.

Os fatores encontrados durante a pesquisa para justificar o atraso vacinal foram crianças fora da faixa etária que representa o maior número de casos, logo em seguida do receio dos pais em adoecer a criança após a vacinação, o esquecimento por parte do responsável e o responsável não quis levar são os que tiveram menores casos relatados.

Segundo Barros MGM et al. (2015), os principais fatores relatados pelos pais ou responsáveis para o descumprimento da cobertura vacinal, foram: o esquecimento, que corresponde (30\%) dos casos, a falta de tempo, que representa $(20 \%)$ dos casos, a falta de imunobiológicos na unidade de saúde, representando $(13,3 \%)$, e $(36,7 \%)$ representa outros fatores relatados.

O principal fator encontrado durante a análise dos dados obtidos na pesquisa para o atraso vacinal foi à criança fora da faixa etária indicada para receber a dose do imunobiológico. Cardoso MRA et al. (2011) mostraram por meio da análise de registros da cobertura vacinal de crianças em um sistema eletrônico de imunização no sul do Brasil, que há uma grande proporção de doses incorretas válidas, ou seja, os imunobiológicos foram administrados em uma idade posterior ou após um intervalo maior do que o que é recomendado pelo programa de imunização.

Para Couto MT e Barbieri CLA (2015), um dos motivos que leva a não vacinação das crianças é a decisão tomada pelos responsáveis de não permitir a vacinação, pois acreditam que as vacinas trarão riscos e ameaça à saúde do filho. Acreditando assim que seus filhos estarão protegidos apenas pelo amor, alimentação, aleitamento materno, condições socioculturais, entre outros modos de vida mais natural, sem que seja necessária interferência científico-tecnológicas.

O adoecimento da criança após aplicação do imunobiológico representou um dos principais fatores citados para justificar o descumprimento do calendário vacinal, pois a mãe sentia "pena da criança" devido adoecer logo após a aplicação. Sato APS et al. (2018) evidenciaram por meio de uma análise de fichas de notificação, que a maioria dos casos de eventos adversos pós-vacinação ocorrem no sexo masculino, representando $(54,0 \%)$ dos casos confirmados, identificando ainda que $(41,7 \%)$ dos casos ocorrem após a primeira dose da vacina. 
Em contrapartida Dona D et al. (2018), perceberam que os dados colhidos nas admissões do Special Service Organization in Padua (SIS-PED) afirma que as alergias representam (53\%) dos casos de internações, porem somente $(19,5 \%)$ foram reações anafiláticas, ou seja, reações relacionadas aos imunobiológicos. Já na pesquisa realizada por Santos GRD et al. (2016) o principal fator que levou ao atraso dos imunobiológicos no calendário básico das crianças, foram a falta de tempo representando cerca de $(21,2 \%)$ dos motivos relatados pelos responsáveis pela criança, em seguida da dificuldade de ir ao posto de vacinação $(6,7 \%)$ e contraindicação médica $(4,9 \%)$.

É relevante salientar que a dificuldade de ir ao posto de saúde devido à locomoção e a situação de moradia foi um dos fatores encontrados, devido morarem longe da unidade de saúde existe uma maior dificuldade de locomoção para levar a criança. Um estudo realizado por Oliveira MAF et al. (2014), mostraram que um fator que leva as mães a não cumprirem o calendário de vacina dos filhos, é a situação de moradia, as dificuldades encontradas na locomoção de sua residência até uma unidade de saúde para a administração do imunobiológico na criança.

À conduta dos profissionais responsáveis pela administração dos imunobiológicos também se encaixam em um dos fatores que possam vir a interferir no cumprimento das metas estabelecidas pelo Ministério da Saúde para o calendário de vacina infantil. O atraso vacinal requer uma necessidade maior de supervisão direta dos profissionais de enfermagem que são responsáveis pelas atividades de imunização, pois a imunização básica é uma das ferramentas utilizadas na promoção e proteção da saúde durante a infância (ABUD SM e GAIVA MAP, 2014).

Brito MP et al. (2014), mostraram em um estudo realizado para observar a perda de oportunidade de vacinação, e os aspectos relacionados à atuação da atenção primária em Recife, Pernambuco, no ano de 2012, que os vacinadores diante do comparecimento do pai ou responsável à unidade de saúde sem o cartão de vacinação da criança, 21 profissionais pediam a este que retornasse com o cartão como condição para realização do procedimento, 8 recorriam ao registro no cartão-espelho e 4 consultavam os agentes comunitários de saúde.

Gomes RNS et al. (2016), identificaram em uma pesquisa realizada em 32 unidades básicas de saúde de um município do Maranhão, que fatores relacionados às matérias de apoio e consumo tão podem levar no descumprimento do calendário básico de vacinação, estão entre eles a ausência de imunobiológicos em salas de vacinas $(88,0 \%)$, ausência de carimbo para registro de vacina $(81,0 \%)$, ausência de álcool $(70,0 \%)$ e ausência de seringas descartáveis $(75,0 \%)$.

$\mathrm{Na}$ concepção Oliveira MFS et al. (2014), ressalta que em alguns procedimentos inadequados relacionados ao cumprimento do calendário vacinal foram encontrados por durante a coleta de dados da Ficha de Notificação de Procedimentos Inadequados, são eles realização do procedimento fora da idade recomendada, em seguida de o intervalo inadequado entre as doses, procedimento não identificado e o tipo de imunobiológico administrado.

\section{CONSIDERAÇÕES FINAIS}

Os fatores que levam ao descumprimento podem ser diversos, desde fatores sociais ou relacionados à saúde, houve um elevado número de crianças fora da faixa etária adequada para a administração do imunobiológico recomendado, o que dificulta assim o alcance da cobertura vacinal. Constatou-se que os principais fatores encontrados foram criança fora da faixa etária, preocupação com o adoecimento da criança adoecia, esquecimento dos pais ou responsáveis, não querer levar a criança a unidade básica de saúde e outros motivos (falta de tempo, falta de imunológico no posto). Enfim, evidenciou-se diante desta problemática abordada, que se torna relevante o desenvolvimento de ações intensificadas por parte da equipe da estratégia da família com intuito de reforçar a captação das crianças faltosas ou com atraso no calendário básico de Vacinação.

\section{REFERÊNCIAS}

1. ABUD SM, GAíVA MAP. Análise do preenchimento dos dados de imunização da caderneta de saúde da criança. Rev. Eletr. Enf., Cuiabá, 2014; 16(1): 61-67. 
2. ANDRADE DRS, et al. Conhecimento de mães sobre o calendário de vacinação e fatores que levam ao atraso vacinal infantil. Cogitare Enferm., Caxias do Sul, 2014; 19(1): 94-100.

3. BRASIL, Ministério da Saúde. Secretaria de Atenção à Saúde. Departamento de Atenção Básica. Política Nacional de Atenção Básica. Brasília: Ministério da Saúde, 2012.

4. Ministério da Saúde. Secretaria de Vigilância em Saúde Brasília. Coberturas vacinais no Brasil Período: 2010 - 2014. Brasília: Ministério da Saúde, 2014.

5. Ministério da Saúde. Secretaria de vigilância em saúde departamento de vigilância epidemiológica coordenação geral do programa nacional de imunizações. Protocolo de Monitoramento Rápido de Cobertura vacinal (MRC) em crianças de 6 meses a < 15 anos de idade pós-campanha de multivacinação. Brasília: Ministério da Saúde, 2017.

6. BARROS MGM, et al. Perda de oportunidade de vacinação: aspectos relacionados à atuação da atenção primária em Recife, Pernambuco. Epidemiol. Serv. Saúde, Recife, 2015; 24(4): 701-710.

7. BRITO MP, et al. Caracterização das notificações de procedimentos inadequados na administração de imunobiológicos em Ribeirão Preto, São Paulo, 2007-2012. Epidemiol. Serv. Saúde, Ribeirão Preto, 2014; 23(1): 3344.

8. CAVALCANTE CCFS, et al. Vacinas do esquema básico para o primeiro ano de vida em atraso em município do nordeste brasileiro. J.Res. Fundam. Care. Online, Floriano, 2015; 7(1): 2034-2041.

9. CARVALHO JVRL, et al. Conhecimento das Mães a Respeito das Vacinas Administradas no Primeiro Ano de Vida. Revista Brasileira de Ciências da Saúde, Picos, 2015; 19(3): 205-210.

10. CARDOSO MRA, et al. Cobertura vacinal em menores de dois anos a partir de registro informatizado de imunização em Curitiba. Rev. Saúde Pública, Curitiba, 2011; 45(1): 90-98.

11. COUTO MT, BARBIERI CLA. Cuidar e (não) vacinar no contexto de famílias de alta renda e escolaridade em São Paulo, SP, Brasil. Rev. Ciência \& Saúde Coletiva, São Paulo, 2015; 20(1): 105-114.

12. DONA D, et al. Special Immunization Service: A 14-year experience in Italy. PloS One, Itália, 2018; 13(4): 23-45.

13. GOMES RNS, et al. Avaliação físico-funcional de salas de vacinas da rede pública municipal de Caxias-MA. J. Res. Fundam. Care, Caxias, 2016; 8(1): 3793-3802.

14. MARTINS AF, et al. Imunização de crianças de 0 a 5 anos na Unidade de Saúde da Família da microárea Parque das Nações do município de Marília: uma contribuição referente à adesão. Rev. Pediatria Moderna. Marília, 2014; 50(5): 222-227.

15. NÓBREGA LAL, et al. Avaliação da implantação dos Centros de Referência de Imunobiológicos Especiais (CRIEs) no Brasil. Revista de Saúde Pública, São Paulo, 2016; 50(58): 1-11.

16. OLIVEIRA MAF, et al. Perfil das crianças e adolescentes em situação de rua usuários de drogas. Revista de Enfermagem UFPE online, 2016; 10(2): 475-484.

17. OLIVEIRA MFS, et al. Fatores associados à cobertura vacinal em menores de cinco anos em Angola. Rev. Saúde Pública; Angola, 2014; 48(6): 906-915.

18. SALLY ET, KENU E. Evaluation of access and utilization of EPI services amongst children 12-23 months in Kwahu Afram Plains, Eastern Region, Ghana. Pan African Medical Journal, Gana, 2017; 28(1): 2-11.

19. SATO APS, et al. Uso de registro informatizado de imunização na vigilância de eventos adversos pós-vacina. Rev. de Saúde Pública, São Paulo, 2018; 52(4): 1-10.

20. SANTOS GRD, et al. Avaliação do monitoramento rápido de coberturas vacinais na Região Ampliada de Saúde Oeste de Minas Gerais. Epidemiol. Serv. Saúde, Minas Gerais, 2016; 25(1): 55-64.

21. TAVARES RE, TOCANTINS FR. Ações de enfermagem na atenção primária e o controle de doenças imunopreveníveis. Rev Bras Enferm. São Paulo, 2015; 68(5): 521-527. 